\title{
ETS1 is associated with cisplatin resistance through IKKa/NF-KB pathway in cell line MDA-MB-231
}

Yuzhu Zhang ${ }^{1,4 \dagger}$, Jingjing Wu ${ }^{1 \dagger}$, Meina Ye ${ }^{1}$, Bing Wang ${ }^{1}$, Jiayu Sheng ${ }^{2}$, Bailing Shi ${ }^{3}$ and Hongfeng Chen ${ }^{1 *}$

\begin{abstract}
Background: Platinum-based drugs are used extensively in neoadjuvant chemotherapy for triple-negative breast cancer (TNBC), but their use can be limited by resistance. In this study, we established cisplatin (DDP) resistant TNBC cells to investigate the potential relationship among ETS1, IKKa/NF-KB and resistance.

Methods: The sensitivity was evaluated by MTT, apoptosis analysis. The intracellular DDP concentration difference was tested by inductively coupled plasma mass spectrometry (ICP-MS) method. Molecular pathological mechanism of DDP resistance was explored by microarray analysis and PPI network analysis. The ETS1, NF-kB signaling change were assessed by western blot and q-PCR in vitro and vivo. The existing binds between ETS1 and the core IKKa promoter were found by luciferase assay and chromatin immunoprecipitation technique (ChIP).

Results: MDA-MB-231/DDP (231/DDP) cell had a higher I $C_{50}$ value of cisplatin, lower intracellular DDP concentration, and lower apoptosis ratio than MDA-MB-231 (231/wt) cell line treated with DDP. Increased ABC transporters were induced by the activation of NF-KB pathway in 231/DDP cells. ETS1, RPL6, RBBP8, BIRC2, PIK3A and RARS were six important genes for DDP-resistance based on PPI network and expression validation. Protein expression of ETS1 and IKKa were significantly up-regulated in 231/DDP cells. However, inhibition of ETS1 expression enhances chemo-sensitivity to DDP and reversed the activation of NF-KB pathway in 231/DDP cells and subcutaneous transplantation tumor in vivo. Moreover, there is existing binds between ETS1 and the core IKKa promoter though luciferase assay and ChIP.
\end{abstract}

Conclusion: This study enables us to understand the functions of ETS1 in TNBC chemotherapy and suggests that ETS1 could be used as a novel marker of poor response to DDP and a potential therapeutic target for TNBC chemotherapy.

Keywords: DDP-resistance, ETS1, NF-KB, IKKa, ShRNA, Survival

\section{Background}

Triple-negative breast cancer (TNBC) is an aggressive histological subtype, which is known as a breast cancer that lacks expression of ER, PR and HER2 [1] and accounts for $15 \%$ of all breast cancer types. Currently, chemotherapy is the main treatment for TNBC [2], such as anthracycline and paclitaxel. However, due to p53

\footnotetext{
*Correspondence: mastcell@aliyun.com

${ }^{\dagger}$ Yuzhu Zhang and Jingjing Wu contributed equally to this work

${ }^{1}$ Department of Breast, Longhua Hospital Affiliated to Shanghai University of TCM, No.725, Wanping South Road, Xuhui District,

Shanghai 200032, China

Full list of author information is available at the end of the article
}

mutation in TNBC anthracycline-related drug resistance has been reported [3]. Cisplatin has an effective role in breast cancer, especially BRCA1-associated cancers, which are normally triple-negative type [4]. A previous study found that the response to DDP-based drugs in breast cancer with $B R C A 1^{C 61 G}$ mutation is poorer than that with homozygous $B R C A 1$ mutation [5]. The secondary mutation contributes to the restoration of reading frame of BRCA1 protein [6]. Therefore, it is supposed that revertant mutation might be a source of resistance to DDP in TNBC.

In our study, the TNBC cell line $231 /$ wt and DDPresistant cell line 231/DDP were used. Differences were 
compared between chemo-sensitivity to different drug agents, intracellular DDP accumulations and apoptosis. We found: all results show that the cells line 231/ DDP have DDP-resistance character; then, increased $\mathrm{ABC}$ transporters are induced by the activation of NF- $\mathrm{kB}$ pathway in 231/DDP cells.; furthermore, ETS1, RPL6, RBBP8, BIRC2, PIK3A and RARS are six important genes for DDP-resistance based on microarray analysis, PPI network and expression validation. However, it had been reported enforced over-expression of ETS1 induced IKK $\alpha$ mRNA and protein expression as well as IKK $\alpha$ promoter activity [7]. Our results suggested that the protein expression of ETS1 and IKK $\alpha$ are significantly up-regulated in 231/DDP cells. In addition, inhibition of ETS1 expression enhanced chemo-sensitivity to DDP and reversed the activation of NF-kB pathway in 231/DDP cells. Besides, stable knocking-down ETS1 increased the efficacy of DDP in mouse xenograft models.

\section{Methods and materials}

\section{Cell lines and cell culture}

The TNBC cell line 231/wt was bought from the cell resource center of Shanghai Institutes for Biological Sciences, Chinese Academy of Sciences. The DDP-resistant human TNBC cell line 231/DDP was obtained by stimulating 231/wt cell lines with different DDP concentrations, as described in our previous work [8]. These cell lines were recovered in the medium without DDP, then was cultured in the medium with DDP $(1.5 \mu \mathrm{g} / \mathrm{mL})$ on the next day in the atmosphere of $5 \% \mathrm{CO}_{2}$ at $37^{\circ} \mathrm{C}$.

\section{Detection of intracellular DDP concentration using ICP-MS method}

The $1 \mu \mathrm{g} / \mathrm{mL}$ DDP was added in both of the 2 cell lines at the logarithmic phase, when the cell inhibitory concentration $\left(\mathrm{IC}_{50}\right)$ value was " 0 ". After $48 \mathrm{~h}$ pretreatment, the supernatant was abandoned, and the cells were washed in PBS for 3 times, and then collected by cell scraper. Thereafter, cells were suspended in lysis buffer containing concentrated nitric acid, and incubated at $60{ }^{\circ} \mathrm{C}$ for $20 \mathrm{~min}$. Then, intracellular DDP concentration was measured. The splitting cells were transferred into a $1.8 \mathrm{~mL}$ EP centrifugal tube, and then put these into liquid nitrogen and water bath for $1 \mathrm{~min}$, respectively. After repeating for 3 times, the DDP concentration was measured based on the inductively coupled plasma mass spectrometry (ICPMS) method [9].

\section{Cell viability}

MTT assay was used to measure the drug resistance of DDP-resistant cell line. In brief, cells were inoculated in the 96-well plate, 5000 cells per well. After $24 \mathrm{~h}$ incubation, if all cells were attached, which could be separately treated with four drugs as DDP, doxorubicin (DOX), paclitaxel and cyclophosphamide (CTX). The specific operation steps is that DDP was dissolved in amide, $n, n$ dimethyl-formicaci (DMF) (2 $\mathrm{mg} / \mathrm{mL}, 6.67 \mathrm{mM})$ then diluted by phosphate buffer solution (PBS). DOX was dissolved in dimethyl sulfoxide (DMSO) $(2 \mathrm{mg} / \mathrm{mL}$, $3.45 \mathrm{mM}$ ) then diluted by PBS. CTX was dissolved in DMSO (2 mg/mL, 7.17 mM) then diluted by PBS. Paclitaxel was dissolved in DMSO $(2 \mathrm{mg} / \mathrm{mL}, 2.34 \mathrm{mM})$ then diluted by PBS. After $48 \mathrm{~h}$ treatment, the cells were incubated in MTT for $4 \mathrm{~h}$, and then DMSO was added and shocked for $10 \mathrm{~min}$. OD value of the survival cells were determined under $490 \mathrm{~nm}$ wave, with the reference under $630 \mathrm{~nm}$. On this basis [10], the $\mathrm{IC}_{50}$ value in each group was calculated.

\section{Flow cytometric analysis of apoptosis}

Extent of apoptosis was measured by Annexin V-FITC apoptosis detection kit (Invitrogen Corporation, California, USA) according to supplier's instruction. Briefly, cells were treated with $1 \mu \mathrm{g} / \mathrm{mL}$ DDP for $48 \mathrm{~h}$, collected and stained with Annexin V-FITC, then analyzed by using FACScan flow cytometer (Becton-Dickinson, Newjersey, USA).

\section{Microarray analysis and PPI network analysis}

There were six samples in the following GeneChip probe array analysis: DDP-resistant (231/DDP, $n=3)$ and nonresistant breast cancer cell lines $(231 / w t, n=3)$. First, total RNAs in each sample were extracted by the TRIzol method (Invitrogen), and then examined by the Agilent 2100 Bioanalyzer (Agilent Technologies, Palo Alto, CA). Next, the RNAs were amplified and labeled using the GeneChip WT PLUS reagent kit (Affymetrix, Santa Clara, CA, USA) according to the manufacturer's instruction. Afterwards, the labeled RNAs were hybridized to Affymetrix GeneChip Human Transcriptome Array 2.0 in hybridization oven (Affymetrix model 640 ) for $16 \mathrm{~h}$ at $45^{\circ} \mathrm{C}[11,12]$.

\section{Quantitative real-time reverse transcription-PCR}

As aforementioned, total RNA was extracted by the TRIzol method (Invitrogen), and was then reversely transcribed into cDNA according to the manufacturer's instruction of the TaqMan reverse transcription kit (Applied Biosystems) (Logan et al. 2006). Following, the quantitative real-time reverse transcription-PCR (qRTPCR) was performed to calculate gene expressions, with GAPDH as the internal reference. Primer sequences of the genes are listed in Table 1. Rotor-Gene6 software was used to calculate the $\mathrm{Ct}$ value, and gene expressions were calculated by $2^{-\Delta \Delta C t}$ method [13]. 
Table 1 Primer sequences of genes

\begin{tabular}{|c|c|c|}
\hline Gene & Primer $\left(5^{\prime}\right.$ to $\left.3^{\prime}\right)$ & $\begin{array}{l}\text { Annealing } \\
\text { temperature } \\
\left({ }^{\circ} \mathrm{C}\right)\end{array}$ \\
\hline \multirow[t]{2}{*}{ ETS1 } & F:TTACTCAGCGCCTCGTCCT & 59.9 \\
\hline & R: GATCCCCAGTCGTTGCTGTT & \\
\hline \multirow[t]{2}{*}{ RPL6 } & F:TCAGAGGAATTGGCAGGTA & 61.4 \\
\hline & R: AGGCACATCTTCAGTAGGA & \\
\hline \multirow[t]{2}{*}{$\mathrm{BIRC3}$} & F:TTGTGATGGTGGCTTGAG & 61.2 \\
\hline & R: AGTGGTATCTGAAGTTGACA & \\
\hline \multirow[t]{2}{*}{ RBBP8 } & F:TGAAGAAGCAAGAGCAGAA & 58.1 \\
\hline & R:TGGAATGTAGCGGAATCG & \\
\hline \multirow[t]{2}{*}{ RARS } & F: GAAGCGAGCATATCAGTGT & 58.3 \\
\hline & R: AGCCAGGTCAGATGTATCA & \\
\hline \multirow[t]{2}{*}{ PIK3A } & F: CGAGGTTTTGCTGTTCGGTG & 62.4 \\
\hline & R: CAGGCCAAACCTCTGGCTAA & \\
\hline
\end{tabular}

\section{Western blot}

Total proteins were extracted and protein concentrations were evaluated using Bradford assay (Pierce Biotechnology Inc., Rock-ford, USA). Western blotting assay was performed as described previously [3]. The antibodies against ETS1(ab26096), MRP2(ab3373), BRCP(ab3380), P-gp(ab103477), P38(ab31828), p-P38(ab45381), IKK $\alpha(\mathrm{ab32041}), \mathrm{IKK} \beta(\mathrm{ab32135})$, and NF-KB (ab16502) were purchased from Abcam.

\section{shRNA transfection}

PHY-310-GFP plasmid expressing human ETS1 was provided by Hanyi Biotechnology Shanghai. For the knockdown experiment, the ETS1 shRNA (5'-CGCUAUACC UCGGAUUACU-3') was cloned into PHY-31-GFP vector. The 231/DDP cells were subcultured in a 6-well plate for $24 \mathrm{~h}$, with a concentration of 70-80\%. 231/DDP was transfected stably PHY-310-GFP-shETS1 by using Lipofectamine $^{\mathrm{TM}} 2000$ Reagent (Invitrogen, USA), followed by selection in $2-\mu \mathrm{g} / \mathrm{mL}$ puromycin. Stable ETS1 knockdown cells were used in the subsequent study.

\section{Immunofluorescence assay}

Cells were placed on a glass slide at the density of $1.0 \times 10^{5}$ cells $/ \mathrm{mL}$. Cultured for $48 \mathrm{~h}$, the cells washed for with PBS and then fixed with $4 \%$ paraformaldehyde for $20 \mathrm{~min}$ at $4{ }^{\circ} \mathrm{C}$. Cells were permeabilized using $0.3 \%$ Triton X-100/PBS for $20 \mathrm{~min}$ and washed with PBS. The cells were then incubated for $30 \mathrm{~min}$ in the $0.5 \%$ BSA. Diluted primary antibody $(1: 50)$ was applied to each coverslip and incubate overnight at $4{ }^{\circ} \mathrm{C}$. After washing in PBS, the cells were incubated with rabt antibody at a 1:200 dilution for $1 \mathrm{~h}$ at room temperature in the dark and followed by
DAPI nuclear staining $(1 \mu \mathrm{g} / \mathrm{mL})$ for $5 \mathrm{~min}$. After washing, the images were taken using a Zeiss Laser Scanning Confocal Microscope (LSM7 DUO).

\section{IKKa promoter and luciferase activity assays}

To construct the IKK $\alpha$ promoter, we amplified the promoter region from -217 to -2216 from transcription start site by PCR using hot-start DNA polymerase (New England Biolabs, Ipswich, Massachusetts, USA). A 3-kb fragment containing KpnI and $\mathrm{XhoI}$ sites was then ligated into the PCR2 vector by using a Plasmid minni Kit I (200) (OMEGA). The promoter fragment was excised from IKK $\alpha$ by digesting it with $K p n I$ and $X h o I$ and then clone in PGL3-Basic vector (IKK $\alpha-\mathrm{NC}$ ) and IKK $\alpha$-luciferase vector (IKK $\alpha-\mathrm{OE})$ to produce promoter luciferase report.

Sub-confluent cells cultured in 6-well plates were transiently co-transfected with luciferase reporter and internal control plasmids, using the DNAfectin Transfection Reagent according to the manufacture's protocol. Cells were lysed in passive lysis buffer, and luciferase assay was performed using dual-luciferase reporter assay kit in $48 \mathrm{~h}$ post transfection. Renilla luciferase activity was used as control for transfection was performed in triplicate.

\section{Chromatin immunoprecipitation (ChIP)}

ChIP was performed using ChIP assay kit (Cell Signaling Technology, CST, USA) according to the manufacture`s instruction. The main step is that cells in a $10-\mathrm{cm}$ culture plate were crosslinked for $10 \mathrm{~min}$ by $1 \%$ formaldehyde. Crosslinking was neutralized by $0.2 \mathrm{M}$ glycine. Cells were collected and suspended in lysis buffer $(25 \mathrm{mM}$ Tris- $\mathrm{HCl}$, $150 \mathrm{mM} \mathrm{NaCl}, 1 \mathrm{mM}$ EDTA, 1\% SDS and 5\% glycerol). Genomic fragments were sonicated to a proper length. Protein-DNA complexes were precipitated with ETS1 antibody or immunoglobulin $\mathrm{G}$ overnight at $4{ }^{\circ} \mathrm{C}$. The complexes were purified by protein A/G magnetic beads and the crosslinks were reversed at $68{ }^{\circ} \mathrm{C}$. Quantitative PCR was performed, after DNA fragments were purified. Primer sequences used in ChIP-qPCR are as follows: IKKa 5'-GTGGTTCCGTTCAGCCCT-3' (Forward), 5'-TGCTCGCGCGTCTTTG-3' (Reverse); U2 5'-ATC GCTTCTCGGCCTTTTGG-3' (Forward), 5'-AGGTCG ATGCGTGGAGTGGA-3' (Reverse).

\section{Mouse xenograft studies}

Four-week old female BALB/C nude mice, weight of 15-16 g, were obtained from Shanghai SLAC Laboratory Animal Company (Shanghai China). The mice were housed specific pathogen-free conditions at $22 \pm 2{ }^{\circ} \mathrm{C}$, at $70 \%$ relative humidity and under a 12-h light/dark cycle. Six-week old female nude mice, approximately $20 \mathrm{~g}$, were transfected 231/DDP cells (sh-ETS1 and empty vector) were harvested at a concentration of $1.0 \times 10^{7}$ cells $/ \mathrm{mL}$ 
and suspended cell $(0.2 \mathrm{~mL})$ subcutaneously implanted into the left second breast fat pad of each mouse. Tumor growth was examined every 3 days, and tumor volume was calculated using the equation $\mathrm{V}=\mathrm{D} \times \mathrm{d}^{2} / 2(\mathrm{~V}$, volume; $\mathrm{D}$, long diameter; $\mathrm{d}$, short diameter). When the average tumor size reached approximately $60 \mathrm{~mm}^{3}$, DDP was administered 2 times per week by intraperitoneal injection at a dose of $4.2 \mathrm{mg} / \mathrm{kg}$. A month after the injection, mice were killed and the subcutaneous growth of each tumor was examined.

\section{Statistical analysis}

The SPSS 19.0 software was used to perform the statistical analysis. $P$ values less than 0.05 were considered significant. All the data were presented using "mean $\pm S D$ ", each experiment was repeated for three times [14].

\section{Results}

Drug resistance and the apoptosis of 231/DDP and 231/wt cell lines

To verify whether 231/DDP [8] had the resistant properties to DDP and multidrug, MTT method was used to detect cell inhibitory rate, namely $\mathrm{IC}_{50}$ of the aforementioned drugs (DDP, DOX, paclitaxel and cyclophosphamide). As presented in Fig. 1a, after $48 \mathrm{~h}$ treatment with DDP, the $\mathrm{IC}_{50}$ of the four drugs in 231/DDP cells were dramatically increased compared with MB-MDA-231 cells, especially the $\mathrm{IC}_{50}$ of DDP (Table 2). Annexin V/ PI assay indicated that after $48 \mathrm{~h}$ cultivation with different concentration of DDP, the apoptosis ratio was significantly lower in 231/DDP group, than 231/wt group (Fig. 1b, c, $P<0.05$ ).

Table 2 IC $_{50}$ and $\mathrm{RI}$ of MDA-MB-231 cells and MDA-MB-231/DDP cells to different drugs of DDP/ CTX/Paclitaxel/DOX after $48 \mathrm{~h}$ treatment

\begin{tabular}{llclll}
\hline Group & \multicolumn{1}{l}{$\mathbf{C}_{\mathbf{5 0}}$ value $(\boldsymbol{\mu} \mathbf{g} / \mathbf{m L}$ mean $\pm \mathbf{S D})$} \\
\cline { 2 - 5 } & MDA-MB-231 & MDA-MB-231/DDP & $\mathbf{R I}$ & $\boldsymbol{P}$ \\
\hline CTX & $3.97 \pm 0.11$ & $10.47 \pm 0.42$ & 2.64 & $<0.001$ \\
Doxorubicin & $2.38 \pm 0.09$ & $6.55 \pm 0.41$ & 2.75 & $<0.001$ \\
DDP & $3.13 \pm 0.12$ & $19.44 \pm 0.89$ & 6.21 & $<0.001$ \\
Paclitaxel & $4.08 \pm 1.36$ & $16.94 \pm 1.69$ & 4.15 & $<0.001$ \\
\hline
\end{tabular}

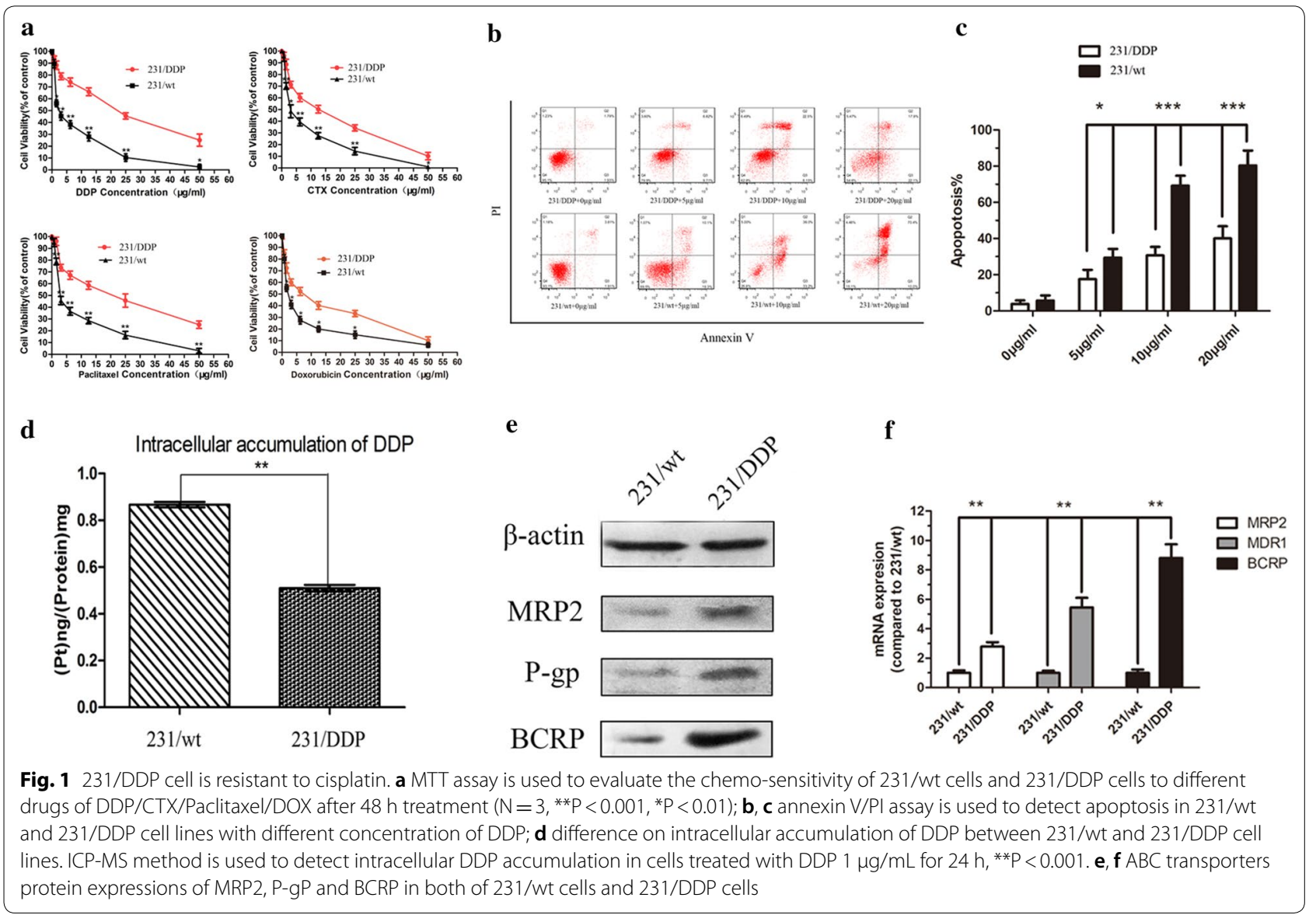


Intracellular accumulation of DDP and $A B C$ transporters alterations in 231/DDP cell lines

Based on ICP-MS detection, we found intracellular DDP concentration was $0.51 \mathrm{ng} / \mathrm{mg}$ in the 231/DDP cell line after $24 \mathrm{~h}$ cultivation with $1 \mu \mathrm{g} / \mathrm{mL}$ DDP complete medium, significantly lower than that in the 231/wt cells (0.87 ng/mg, $P<0.01$, Fig. 1d). To further verify the drug resistance, western blot and $\mathrm{qRT}-\mathrm{PCR}$ was conducted to detect the ABC transporters expressions of MRP2, P-gP and $\mathrm{BCRP}$, three known proteins related to drug resistance on membrane, in both of 231/wt cells and 231/DDP cells. As expected, mRNA and protein expressions of them were obviously increased in 231/DDP cells, compared with 231/wt cells (Fig. 1e, f).

ETS1 was over expressed in 231/DDP cell line by microarray experiment, PPI network analysis and qRT-PCR

Based on the aforementioned selection criteria $(\mathrm{P} \leq 0.05$ and FC $>1$ ), a set of 895 DEGs were identified between 231/wt cell line and 231/DDP cell line, which could well distinguish the two kinds of cell lines (Fig. 2a). Based on information in the STRING database, a PPI network for the DEGs was constructed. A node in the PPI network represents a protein product of a DEG, and an edge denotes an interaction between two genes. Degree of a node represents the interplayed protein numbers with this gene. Among the PPI network, several nodes had relatively high degrees, such as RPL6 (degree $=2$ ), RBBP8 (degree $=3)$, ETS1 (degree=7), BIRC2 (degree=5), PIK3A (degree =4) and RARS (degree=4) (Fig. 2b). Integrating information in the PPI network with DEGs, the highlighted gene was used as a key word to search drugresistant genes in databases such as the PubMed, in combination with words of "multidrug resistance (MDR)" or "drug resistance" OR "chemotherapy resistance". The above six predominant nodes in PPI network have been reported in the literature, thus their expressions were validated in vitro.

Results of qRT-PCR revealed that gene expressions of ETS1, RPL6, BIRC3, RBBP8, RARS and PIK3A in 231/ DDP cells were all increased compared to 231/wt cells, especially the expression of ETS1 (Fig. 3a). Protein expression via western blot indicated that ETS1 protein was dramatically increased in 231/DDP cell line, compared with 231/wt cell line (Fig. 3b), suggesting this gene's alteration at both mRNA and protein level was tied up with drug resistance to DDP in 231/DDP cell line.

\section{ETS1 expression was correlated with survival of BC}

K-M curve [15] showed that the median survival of breast cancer patients in ETS1 low-expression group was 8.3 months, significantly longer than that in high-expression group with 4.4 months $(P=0.0112$, Fig. $3 c)$. Besides, the HR of the ETS1 level conducted by univariate Cox proportional hazards regression method was 0.401 (CI $0.198,0.812$ ).

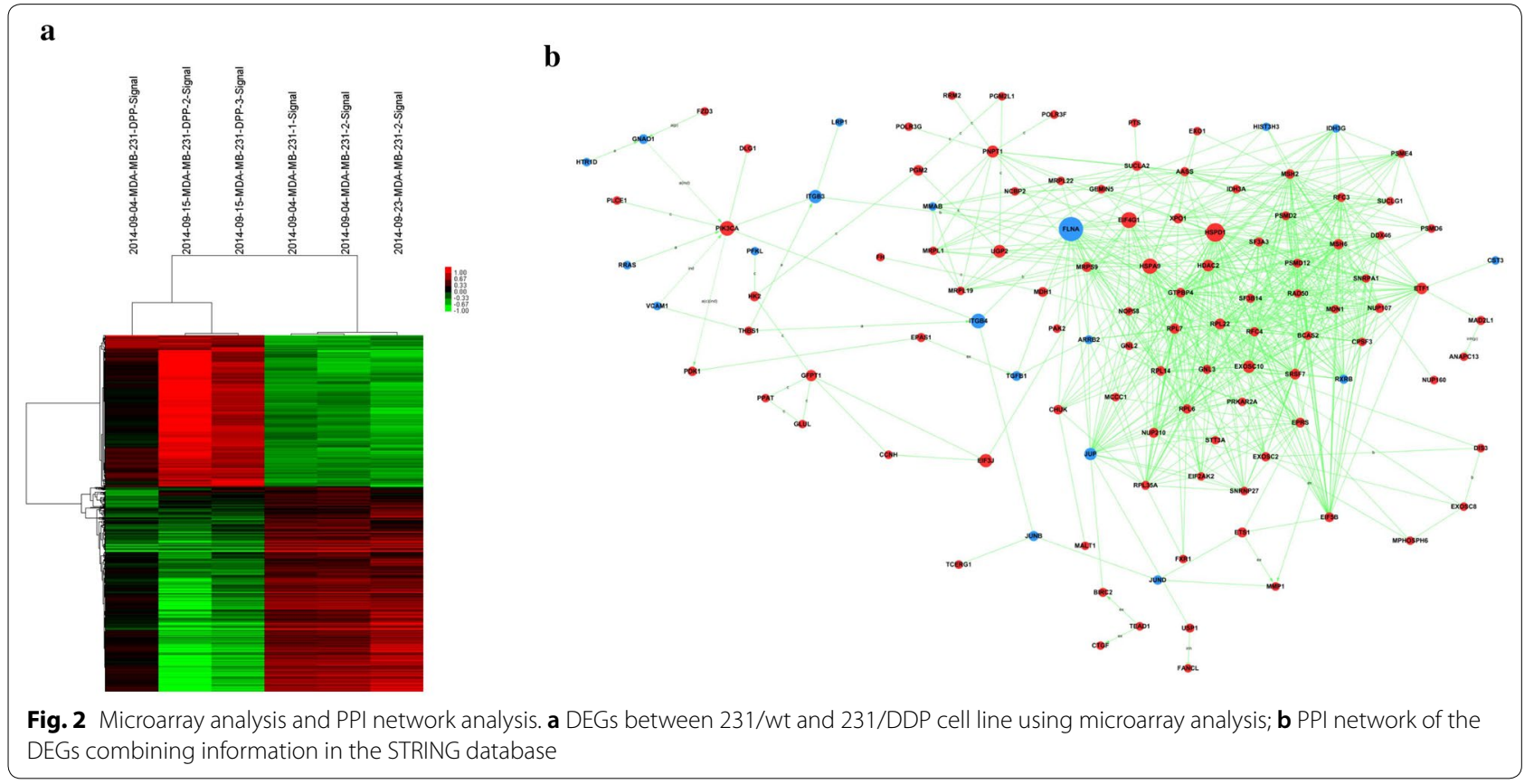




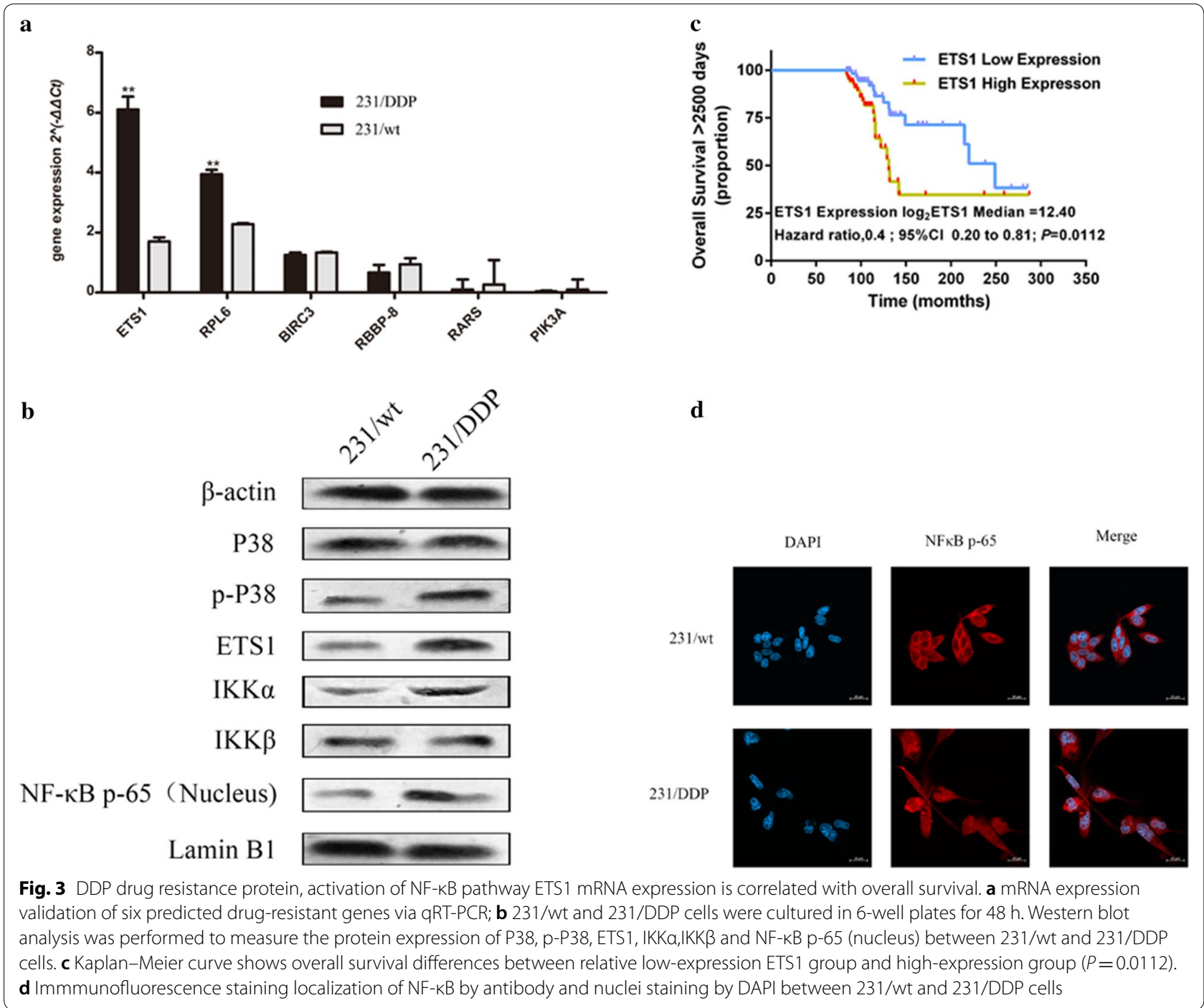

\section{Cisplatin resistance was induced byETS1/IKKa/NF-KB signalling}

The downstream effector of P38/ETS1 signaling was identified by cisplatin resistanc. The translocation of NF-KB in 231/DDP cells was determined by using immunofluorescence staining (Fig. 3d). In addition, the expression of P38, phosphor-P38, ETS1, IкB kinase $\alpha$ (IKK $\alpha)$ and $I \kappa B$ kinase $\beta(I K K \beta)$ as well as $N F-\kappa B$ was determined. Cisplatin resistance induced the high expression of ETS1, IKK $\alpha$, NF- $\mathrm{B}$ and phosphor-P38 (Fig. 3b). Moreover, it is noting that cisplatin resistance by the high expression of IKK $\alpha$ and further affecting up-regulation expression of NF- $\mathrm{kB}$, not IKK $\beta$ which $\mathrm{IKK} \beta$ is considered as classic path way to activate NF-кB [16].

\section{Inhibition of ETS1 expression enhances chemo-sensitivity} to DDP in 231/DDP cell lines

After ETS1 knocking down, the resistance to four drugs as DDP, DOX, paclitaxel and cyclophosphamide in 231/ DDP cell was remarkably reduced; especially to DDP, whose $\mathrm{IC}_{50}$ was significantly reduced from 19.62 to 2.92 $(P<0.001$, Fig. 4a; Table 3$)$. ICP-MS detection results showed that intracellular DDP concentration was significantly increased in 231/DDP-KD cell line, compared to that in the $231 / \mathrm{DDP}$ cell $(P<0.001$, Fig. $4 \mathrm{~b})$. With different concentration of DDP, the apoptosis ratio was significantly higher in 231/DDP-KD cell lines than 231/ DDP cell lines (Fig. 4c, d). These results suggest ETS1 inhibition enhances chemo-sensitivity to DDP in 231/ DDP cell lines. 


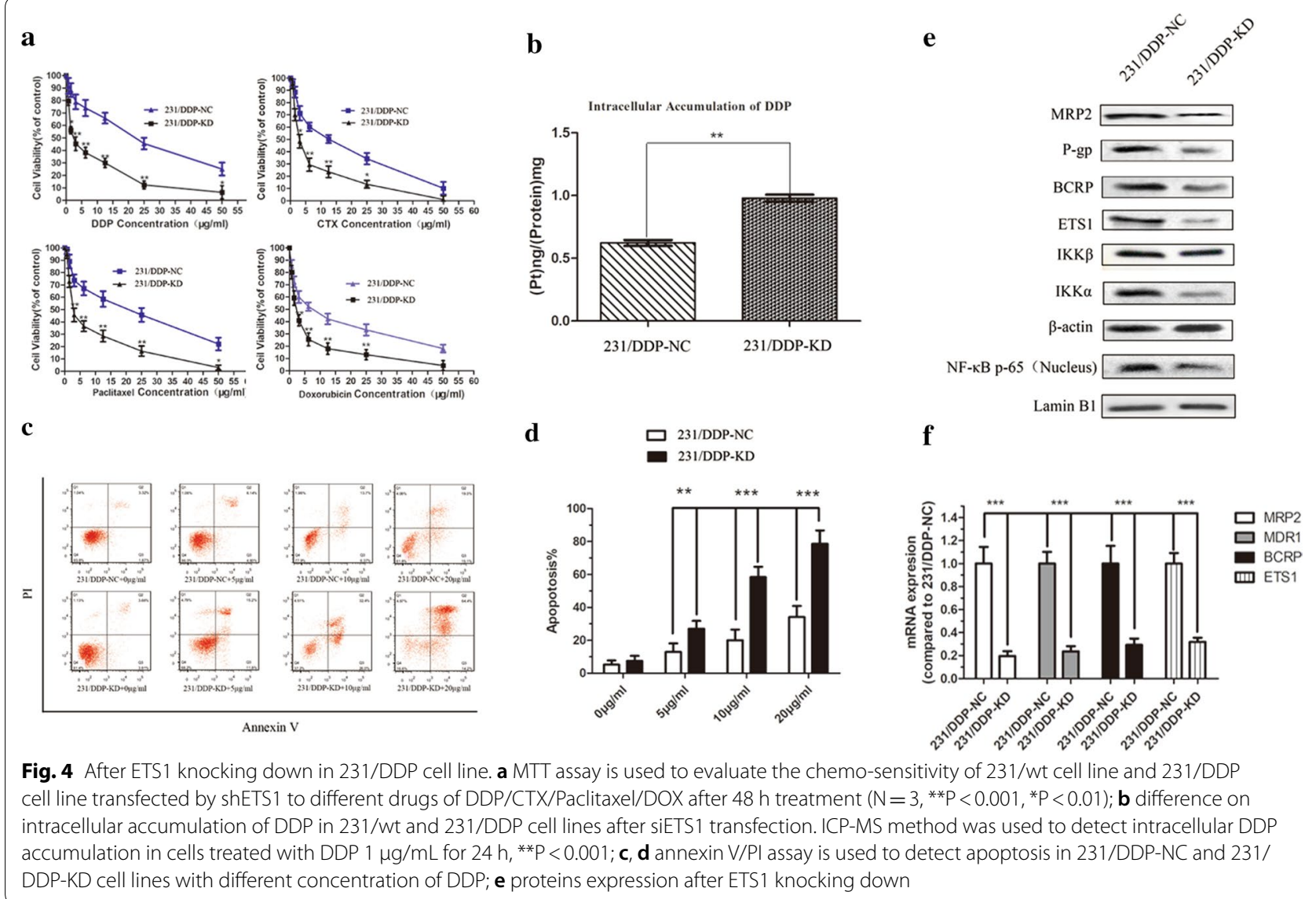

Table $3 I_{50}$ and RI of MDA-MB-231/DDP, NC and ETS1-KD cells to different drugs of DDP/CTX/Paclitaxel/DOX after $48 \mathrm{~h}$ treatment

\begin{tabular}{lcccc}
\hline Group & \multicolumn{1}{l}{$\mathbf{I C}_{\mathbf{5 0}}$ value $(\boldsymbol{\mu \mathbf { g }} \mathbf{\mathbf { m L }}$ mean $\pm \mathbf{S D})$} & & \\
\cline { 2 - 5 } & $\mathbf{N C}$ & ETS1-KD & RI & $\boldsymbol{P}$ \\
\hline CTX & $10.32 \pm 1.63$ & $3.47 \pm 0.55$ & 3.02 & $<0.001$ \\
Doxorubicin & $7.14 \pm 1.08$ & $2.42 \pm 0.33$ & 2.55 & $<0.001$ \\
DDP & $19.11 \pm 3.65$ & $2.92 \pm 0.53$ & 6.43 & $<0.001$ \\
Paclitaxel & $16.05 \pm 3.16$ & $3.89 \pm 0.72$ & 3.97 & $<0.001$ \\
\hline
\end{tabular}

\section{Proteins expression after ETS1 knocking down}

After ETS1 knocking down, protein expression of ETS1 was remarkably reduced in the 231/DDP cell line, compared to the blank control (NC) (Fig. 4e), indicating ETS1 expression was successfully inhibited. ABC transporters and IKK $\alpha$ as well as NF-KB were also decreased in 231/ DDP cell with ETS1-KD (Fig. 4e), suggesting the 231/ DDP cell line might be more sensitive to ETS1 alterations and ETS1 could be the upstream effector of IKK $\alpha$ and $\mathrm{NF}-\kappa \mathrm{B}$.

\section{IKKa promoter activity and mRNA expression were regulated by ETS1 binding}

Promoter analysis of IKK $\alpha$, using PROMO TOOL V. 8.3 of TRANSFAC [17] (Beverly, MA, USA), indicated the presence of ETS1 transcription factor putative-binding sites that cluster into four main regions (Fig. 5a). To validate the elements for regulation in the IKK $\alpha$ promoter region by ETS1, we generated one pCDNA3.1-based luciferases constructs of IKK $\alpha$ containing clusters A, B, C, D (Fig. 5b). A luciferase reporter assay revealed that IKK $\alpha$ Luc in 231/DDP-NC was higher than 231/DDP-KD. This results suggest that ETS1 has one or some clusters for regulatory promoter element for regulation of IKK $\alpha$. ChIP assay was performed, In comparison with control IgG, the IKK $\alpha$ promoter had increased (3.3- to 7.8-fold) expression in 231/wt and 231/DDP. The result strongly induced ETS1 to bind to the IKK $\alpha$ promoter over time. No enrichment was observed in the control IgG group (Fig. 5c). 


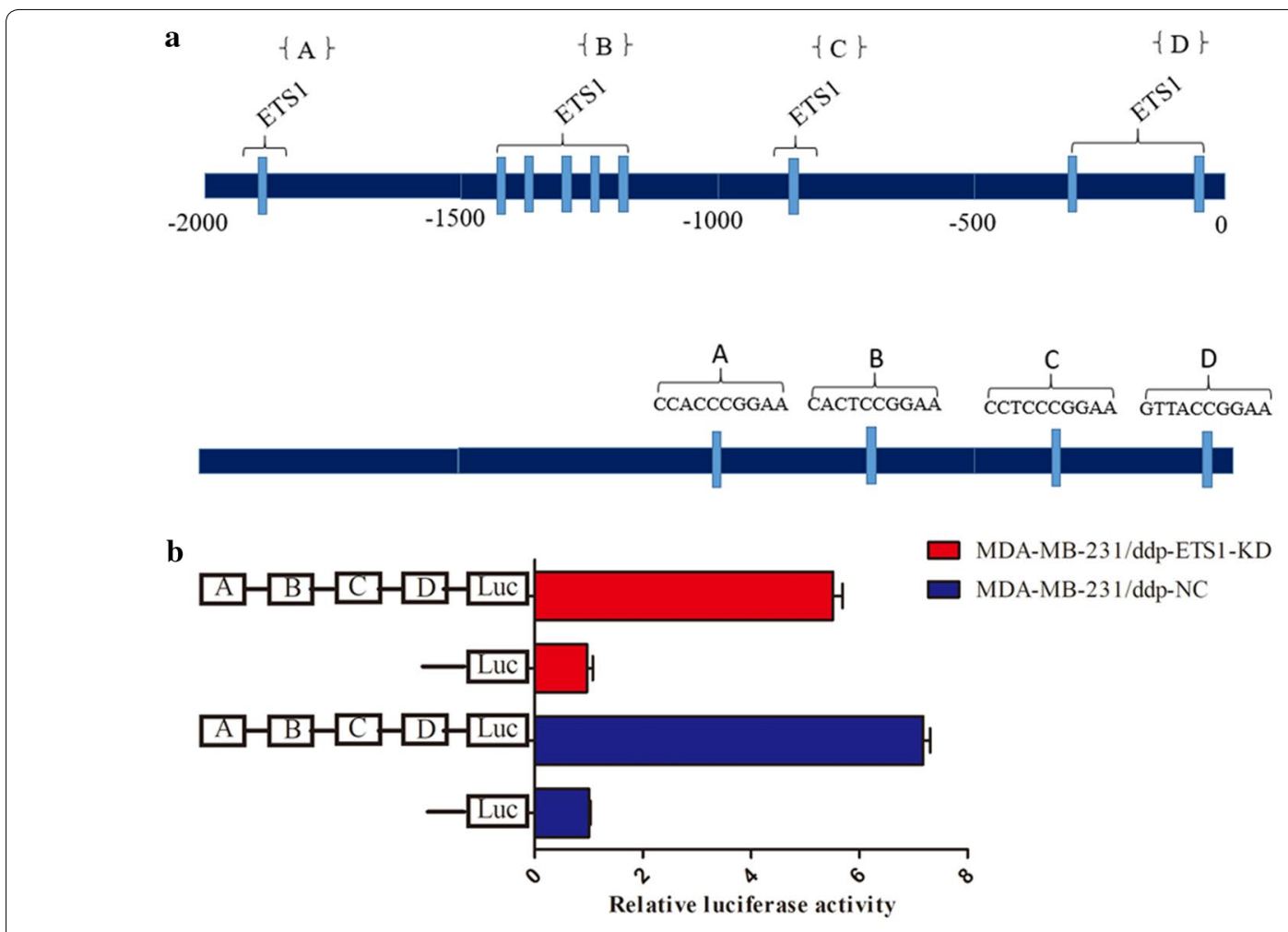

c

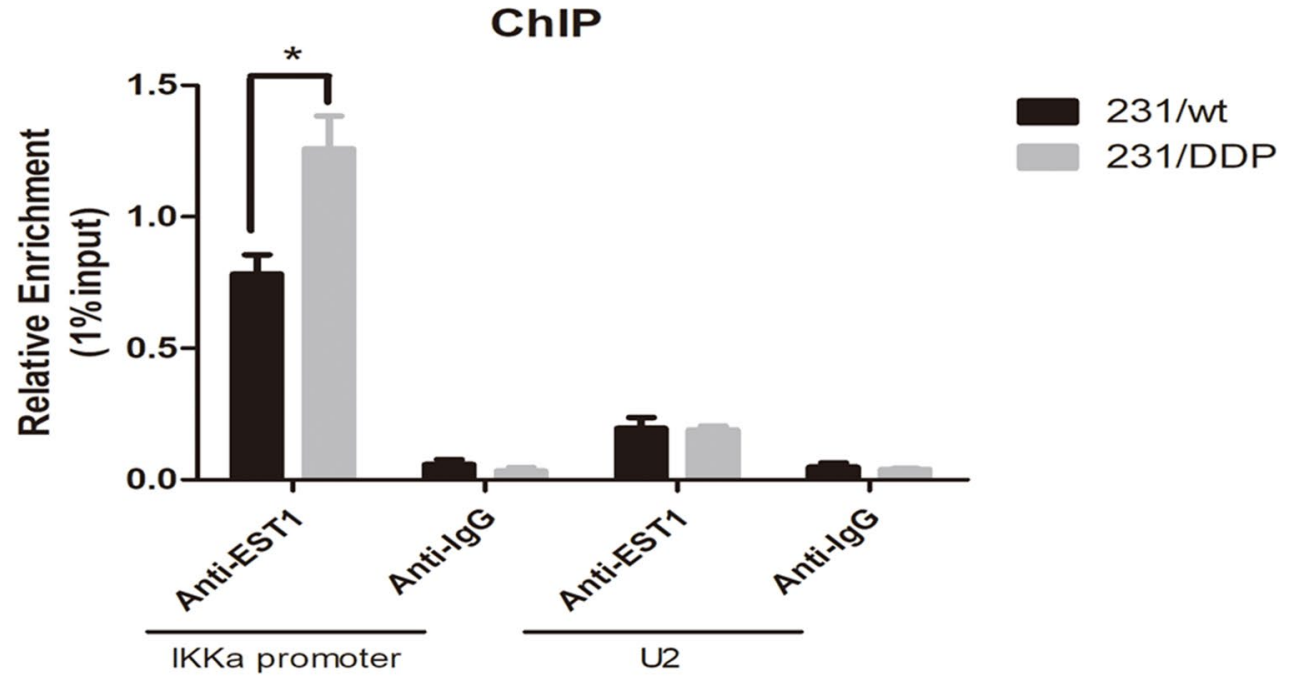

Fig. 5 IKKa promoter activity and mRNA expression were regulated by ETS1 binding. a Indicated the presence of ETS1 transcription factor putative-binding sites that cluster into four main regions; b luciferase reporter assay revealed that IKKa-Luc in 231/DDP-NC was higher than 231/ DDP-KD. c ChIP was performed using an anti-ETS1 antibody or a negative control IgG antibody in 231/DDP and 231/wt cells. Immunoprecipitated DNA was subjected to RT-qPCR using specific IKKa primers that included the ETS1 binding sites

Down-regulation ETS1 improves the vivo sensitivity to DDP To further investigate the underlying roles of ETS1 in enhancing the chemosensitivity of TNBC cell to DDP, we used nude mice xenograft model. 231/DDP cells transfected with shETS1 or empty vector were subcutaneously injected into mice, and followed by treatment with DDP. A month after the initial DDP treatment, the body weight, volume and average weight of tumor xenograft was recorded (Fig. 6a-e). Immunofluorescence staining was used to detect localization and expression level of ETS1 in tumors tissue (Fig. 6f). As shown in Fig. 6d, the tumors formed from shETS1-transfected 

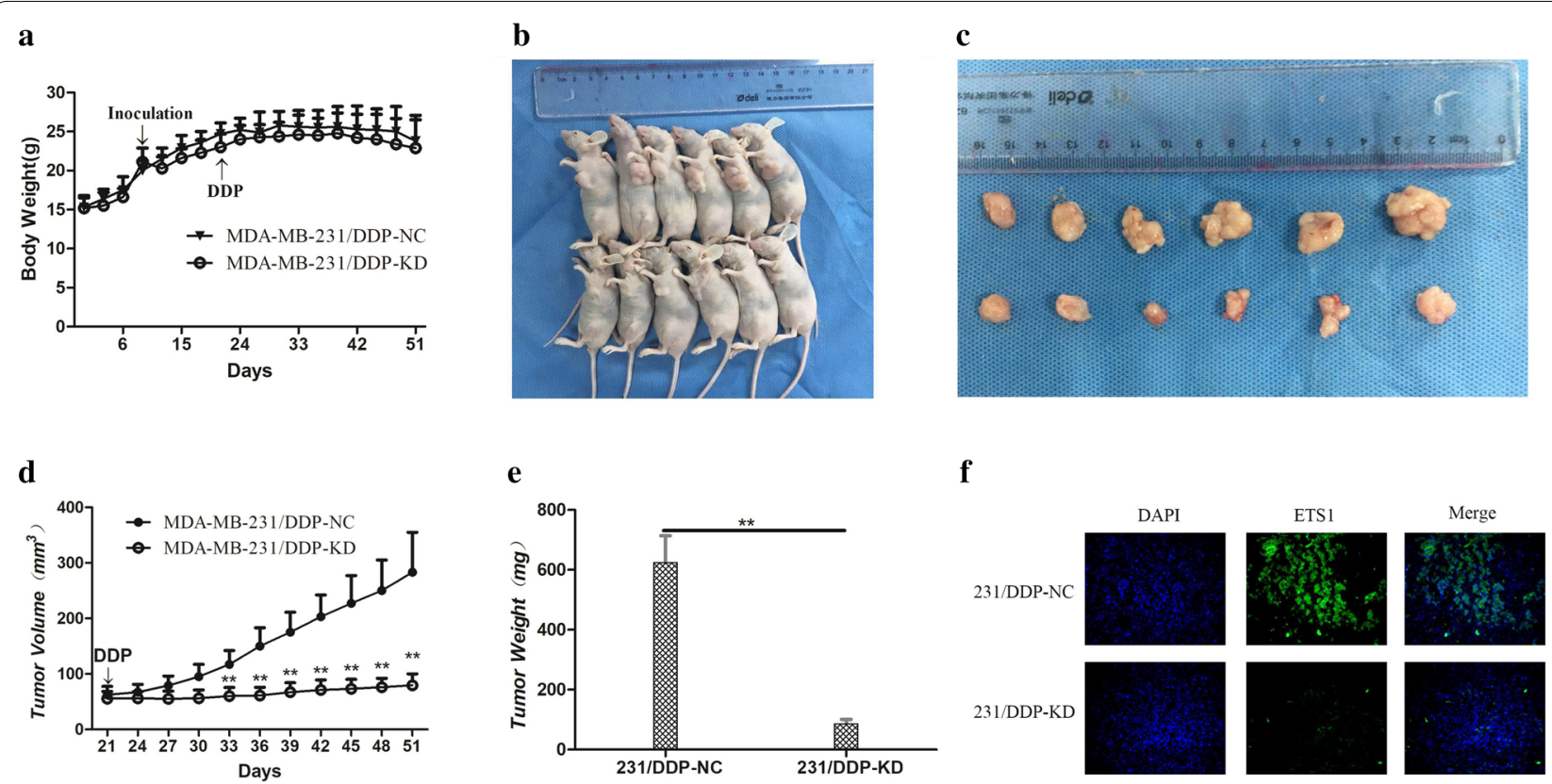

Fig. 6 Down-regulation ETS1 improves the vivo sensitivity to DDP. a The average weight of mice were recorded every 3 days; $\mathbf{b}, \mathbf{c}$ a month after initial cisplatin administration, the tumor volume and average weight receiving PCDNA-ETS1- or empty vector-transfected 231/DDP cells were recorded; $\mathbf{d}$ tumor volume was calculated every 3 days after cisplatin treatment; $\mathbf{e}$ a month after initial cisplatin administration, the tumor average weight receiving pCDNA-ETS1- or empty vector-transfected 231/DDP cells were recorded; ${ }^{*}<<0.05$, ${ }^{*} P<0.01$. f Tumors developed from PCDNA-ETS-transfected 231/DDP cells showed lower ETS1 protein levels by immunofluorescence staining; $\times 400$

231/DDP cells grew significantly more slowly than those from empty vector following DDP treatment. It was also observed that the down-regulation of ETS1 led to the inhibition of tumor growth. These results suggested that ETS1 low expression increased the in vivo chemosensitivity of TNBC cells to DDP.

\section{Discussion}

Drug resistance is a major barrier in cancer treatment [18]. Although DDP has been applied for TNBC treatment, drug resistance is detected. In the present study, 231/DDP cell line had a higher $\mathrm{IC}_{50}$ value of DDP than 231/wt cell line (Fig. 1a). Meanwhile, 231/DDP cell line had a lower intracellular DDP concentration compared with 231/wt cell line, indicating 231/DDPcell line had a higher excretive ability of DDP, which might explain its strong drug resistance. Moreover, expressions of three drug-resistant membrane proteins (MRP1, P-gP and BCRP) $[19,20]$ were remarkably increased in 231/DDP cell line. Collectively, these might be the physiochemical and molecular basis of DDP-drug resistance mechanisms.

ETS1 is a TF regulates genes involved in stem cell development, tumor genesis and metastasis [21]. In drug-resistant MCF-7 breast cancer cells, ETS1 is overexpressed and results in up-regulation of MDR1 [22]. Thus, down-regulation of ETS1 via shRNA stably transfection might be a promising treatment for MDR breast cancer therapy [23]. MiR-200c counteracts trastuzumab resistance by suppressing TGF- $\beta$ signaling and targeting ZEB1 in breast cancer [24]. ETS1 could regulate expression of ZEB1 [25], implying that targeting ETS1 might also counteract the drug resistance. In MCF-7/ADR cells, silencing of ETS1 by down-regulating MDR1 reverses adriamycin resistance [22]. Consistent with these previous studies, in our study, ETS1 was overexpressed in 231/DDP-resistant cell line via microarray analysis and expression validation experiment (Fig. 4). Meanwhile, down-regulation of ETS1 via shRNA stably transfection remarkably increased DDP response by reducing $\mathrm{IC}_{50}$ to $\mathrm{DDP}$ and increasing intracellular DDP concentration (Fig. 4). These give potent evidence that knockdown ETS1 might be an effective strategy to reverse DDP-resistance in TNBC.

In our study, we used public data deposited in TCGA database [26] and performed survival analysis in breast cancer with different ETS1 expressions, and found high ETS1 expression was significantly associated with poor survival in breast cancer (Fig. 3c), which was consistent with previous findings.

Activation of the NF- $\mathrm{BB}$ canonical pathway, leading to the translocation of NF- $\kappa B$ into the nucleus, is one of the strategies which leading cancer cells become drug resistance [27]. Signaling of ETS1/P38 has been proposed to 


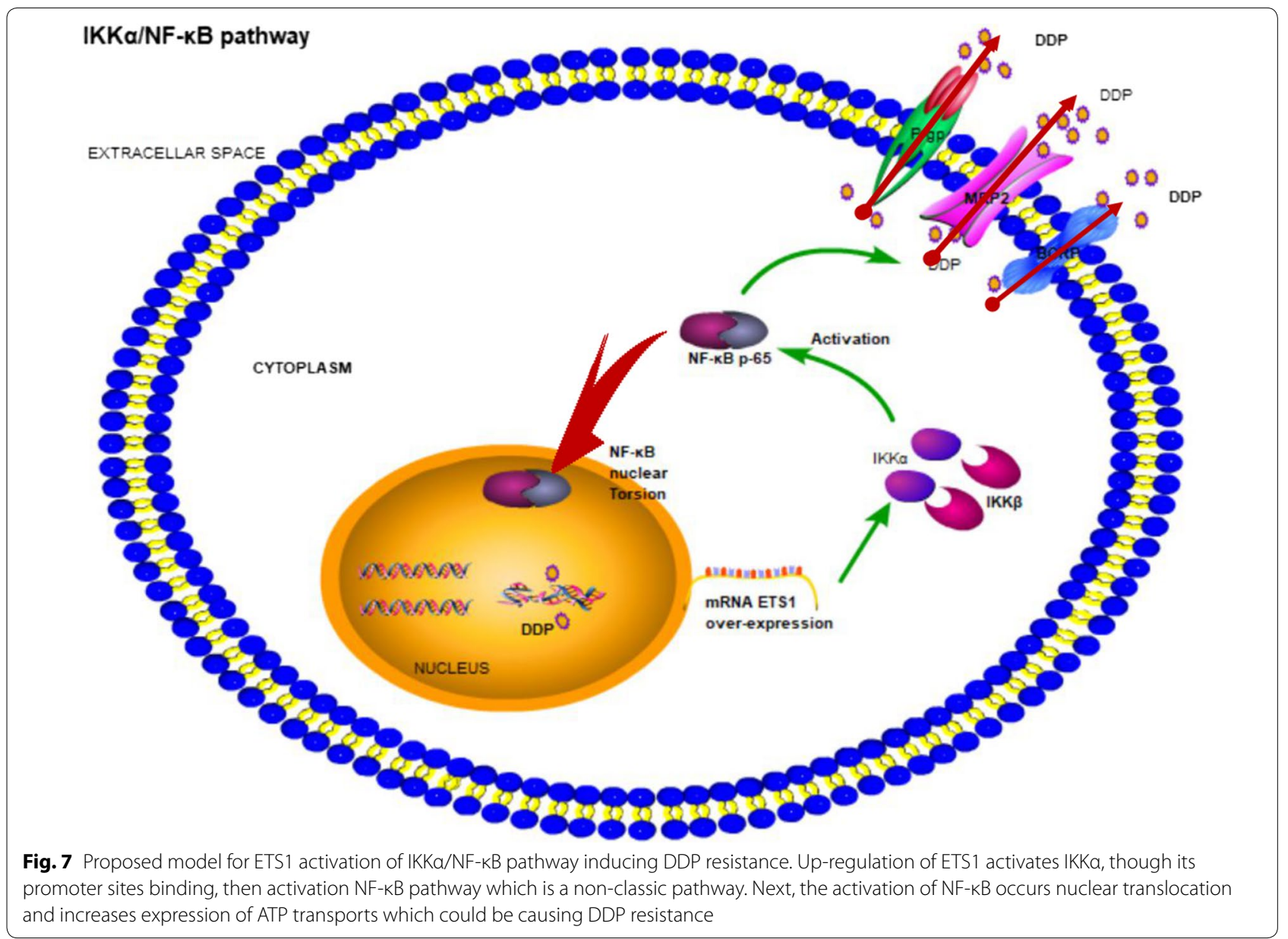

play an important role in the development of tumor [25, 28-31]. Several studies have revealed that ETS1 is overexpression in drug resistant cancer cells [21-23]. As our research found that the high expression of ETS1 and IKK $\alpha$, not IKK $\beta$,in 231/DDP cells. On the other hand, the binding of ETS1 leads the down-regulation expression of IKK $\alpha$ and $A B C$ transporters. Thus, we hypothesize that high expression of ETS1 may influence the activation of NF-kB [32], though the IKK $\alpha$ pathway not IKK $\beta$ and further leading to down-regulation of $A B C$ transporters. Our team has proved it though luciferase assay and chromatin immunoprecipitation technique (ChIP).

\section{Conclusions}

Our data demonstrated that the dysregulation of ETS1 underlies the DDP resistance of TNBC, indicating that its overexpression may contribute to increased DDP chemosensitivity by enhancing $\mathrm{ABC}$ transporters via IKK $\alpha /$ NF-kB path way (Fig. 7). This study enables us to understand the functions of ETS1 in TNBC chemotherapy and suggests that ETS1 could be used as a novel marker of poor response to DDP and a potential therapeutic target for TNBC chemotherapy.

\section{Abbreviations}

TNBC: triple-negative breast cancer; DDP: cisplatin ICP-MS:inductively coupled plasma mass spectrometry; ChIP: chromatin immunoprecipitation technique; 231/DDP: MDA-MB-231/DDP; 231/wt: MDA-MB-231; IC: inhibitory concentration; DOX: doxorubicin; CTX: cyclophosphamide; DMF: amide,n,n-dimethylformicaci; PBS: phosphate buffer solution; DMSO: dimethyl sulfoxide; qRT-PCR: quantitative real-time reverse transcription-PCR.

\section{Authors' contributions}

YZ and JW performed the experiments. YZ performed the data analyses and wrote the manuscript. MY helped perform the analysis with constructive discussions. BW contributed significantly to analysis and manuscript preparation. JS and BS prepared for the study. $\mathrm{HC}$ contributed to the conception of the study. All authors read and approved the final manuscript.

\section{Author details}

${ }^{1}$ Department of Breast, Longhua Hospital Affiliated to Shanghai University of TCM, No.725, Wanping South Road, Xuhui District, Shanghai 200032, China. ${ }^{2}$ Department of Breast Surgery, Shanghai Yueyang Hospital of Integrated Traditional Chinese and Western Medicine, Shanghai, China. ${ }^{3}$ Department of Thyroid and Breast Surgery, The Third Affiliated Hospital of Zhejiang University of Traditional Chinese Medicine, Hangzhou, China. ${ }^{4}$ Department of Mammary Disease, Guangdong Provincial Hospital of Chinese Medicine, Guangzhou, Guangdong, People's Republic of China. 


\section{Acknowledgements}

This research is supported by the National Natural Science Foundation of China (Grant No. 81373647).

\section{Competing interests}

All authors declare that they have no competing interests.

\section{Availability of data and materials}

Please contact author for data requests.

\section{Consent for publication}

Not applicable.

\section{Ethics approval and consent to participate}

This article does not contain any studies with human participants performed by any of the authors. Our study mainly focus on cell line 231/wt and the expression of ETS1 was extracted from the RNA-Seq data from patients with breast cancer, which were computed on IlluminaHiSeq RNASeq platform, were gained from The Cancer Genome Atlas (TCGA) (https://tcga-data.nci.nih. gov/tcga/).

All animal experiments were performed according to the National Institutes of Health Guide for the Care and Use of Laboratory Animal. The protocol was approved by Shanghai University of TCM/Institutional Animal Care and Use Committee and under the guidelines of the "Principles of Laboratory Animal Care" (NIH publication No. 80-23, revised 1996) and Institutional Animal Care and Use Committees protocol (HBFM3.68-2015).

\section{Funding}

This research is supported by the National Natural Science Foundation of China (Grant No. 81373647). National Natural Science Fund for youth (Grant No. 81704074) achieved by co-first author Jingjing Wu.

\section{Publisher's Note}

Springer Nature remains neutral with regard to jurisdictional claims in published maps and institutional affiliations.

Received: 24 March 2018 Accepted: 12 June 2018 Published online: 19 June 2018

\section{References}

1. Foulkes WD, Smith IE, Reis-Filho JS. Triple-negative breast cancer. N Engl J Med. 2010;363:1938-48.

2. Cleator S, Heller W, Coombes RC. Triple-negative breast cancer: therapeutic options. Lancet Oncol. 2007;8:235.

3. Hosoda M, Yamamoto M, Nakano K, Hatanaka KC, Takakuwa E, Hatanaka Y, Matsuno Y, Yamashita $H$. Differential expression of progesterone receptor, FOXA1, GATA3, and p53 between pre- and postmenopausal women with estrogen receptor-positive breast cancer. Breast Cancer Res Treat. 2014;144:249-61.

4. Byrski T, Gronwald J, Huzarski T, Grzybowska E, Budryk M, Stawicka M, Mierzwa T, Szwiec M, Wiśniowski R, Siolek M. Response to neo-adjuvant chemotherapy in women with BRCA1-positive breast cancers. Breast Cancer Res Treat. 2008;108:289-96.

5. Drost R, Bouwman P, Rottenberg S, Boon U, Schut E, Klarenbeek S, Klijn C, Heijden IVD, Gulden HVD, Wientjens E. BRCA1 RING function is essential for tumor suppression but dispensable for therapy resistance. Cancer Cell. 2011;20:797.

6. Byrski T, Dent R, Blecharz P, Foszczynskakloda M, Gronwald J, Huzarski T, Cybulski C, Marczyk E, Chrzan R, Eisen A. Results of a phase II open-label, non-randomized trial of cisplatin chemotherapy in patients with BRCA1 -positive metastatic breast cancer. Breast Cancer Res. 2012;14:R110.

7. Gu L, Zhu N, Findley HW, Woods WG, Zhou M. Identification and characterization of the IKKalpha promoter: positive and negative regulation by ETS-1 and p53, respectively. J Biol Chem. 2004;279:52141.

8. Sheng JY, Shi BL, Chen HF. Establishment and appraisal of DDP resistant variant of triple negative breast cancer cell line MDA-MB-231. Cancer Res Prev Treat. 2016:43:175-80.
9. Martín-Cameán A, Jos A, Calleja A, Gil F, Iglesias-Linares A, Solano E, Cameán AM. Development and validation of an inductively coupled plasma mass spectrometry (ICP-MS) method for the determination of cobalt, chromium, copper and nickel in oral mucosa cells. Microchem J. 2014;114:73-9.

10. Xie F, Li BX, Kassenbrock A, Xue C, Wang X, Qian DZ, Sears RC, Xiao X. Identification of a potent inhibitor of CREB-mediated gene transcription with efficacious in vivo anticancer activity. J Med Chem. 2015;58:5075-87.

11. Das A, Datta S, Rhea B, Sinha M, Veeraragavan M, Gordillo G, Roy S. The human skeletal muscle transcriptome in response to oral Shilajit supplementation. J Med Food. 2016;19:701-9.

12. Gao J, Aksoy BA, Dogrusoz U, Dresdner G, Gross B, Sumer SO, Sun Y, Jacobsen A, Sinha R, Larsson E. Integrative analysis of complex cancer genomics and clinical profiles using the cBioPortal. Sci Signal. 2013;6:11.

13. Livak KJ, Schmittgen TD. Analysis of relative gene expression data using real-time quantitative PCR and the 2(-Delta Delta C(T)) method. Methods. 2001;25:402-8.

14. S.J. Coakes, L. Steed, SPSS: Analysis without Anguish using Spss Version 14.0 for Windows.

15. Kuo TM, Chang KM, Cheng TI, Kao KJ. Clinical factors predicting better survival outcome for pulmonary metastasectomy of hepatocellular carcinoma. Liver Cancer. 2017;6:297-306.

16. Wang D, Chen J, Li R, Wu G, Sun Z, Wang Z, Zhai Z, Fang F, Guo Y, Zhong Y. PAX5 interacts with RIP2 to promote NF-KB activation and drug-resistance in B-lymphoproliferative disorders. J Cell Sci. 2016;129:2261.

17. Janmaat VT, Van DWA, Peppelenbosch MP, Spaander MC, Uitterlinden AG, Pourfarzad F, Tilanus HW, Rygiel AM, Moons LM, Arp PP. Vitamin D receptor polymorphisms are associated with reduced esophageal vitamin D receptor expression and reduced esophageal adenocarcinoma risk. Mol Med. 2015;21:346-54

18. Berveiller P, Marty O, Vialard F, Mir O. Use of anticancer agents in gynecological oncology during pregnancy: a systematic review of maternal pharmacokinetics and transplacental transfer. Expert Opin Drug Metab Toxicol. 2016;12:1.

19. Mao Z, Zhou J, Luan J, Sheng W, Shen X, Dong X. Tamoxifen reduces P-gp-mediated multidrug resistance via inhibiting the PI3K/Akt signaling pathway in ER-negative human gastric cancer cells. Biomed Pharmacother. 2014;68:179-83.

20. Riches Z, Walia G, Berman JM, Wright TE, Collier AC. ATP-binding cassette proteins BCRP, MRP1 and P-gp expression and localization in the human umbilical cord. Xenobiotica. 2016;46:548.

21. Kars MD, Ișeri ÖD, Gündüz U. Drug resistant breast cancer cells overexpress ETS1 gene. Biomed Pharmacother. 2010;64:458-62.

22. Wei J, Zhou Y, Jiang GQ, Xiao D. Silencing of ETS1 reverses adriamycin resistance in MCF-7/ADR cells via downregulation of MDR1. Cancer Cell Int. 2014;14:22.

23. Wu M, Liu X, Jin W, Li Y, Li Y, Hu Q, Chu PK, Tang G, Ping Y. Targeting ETS1 with RNAi-based supramolecular nanoassemblies for multidrug-resistant breast cancer therapy. J Control Release. 2017;253:110-21.

24. Bai WD, Ye XM, Zhang MY, Zhu HY, Xi WJ, Huang X, Zhao J, Gu B, Zheng GX, Yang AG. MiR-200c suppresses TGF- $\beta$ signaling and counteracts trastuzumab resistance and metastasis by targeting ZNF217 and ZEB1 in breast cancer. Int J Cancer J Int Du Cancer. 2014;135:1356-68.

25. Sinh ND, Endo K, Miyazawa K, Saitoh M. Ets1 and ESE1 reciprocally regulate expression of ZEB1/ZEB2, dependently on ERK1/2 activity, in breast cancer cells. Cancer Sci. 2017;108:952-60.

26. Radovich M, Jr SG. TCGA's breast cancer project may yield important therapeutic benefits, but it's too early to be sure. Oncology. 2013;27:1280-2.

27. Fowler KA, Jania CM, Tilley SL, Panoskaltsis-Mortari A, Baldwin AS, Serody JS, Coghill JM. Targeting the canonical NF-KB pathway with a high potency IKK2 inhibitor improves outcomes in a mouse model of idiopathic pneumonia syndrome. Biol Blood Marrow Transplant. 2017;23:569-80.

28. Jung HH, Lee $\mathrm{SH}$, Kim JY, Ahn JS, Park YH, Im YH. Statins affect ETS1overexpressing triple-negative breast cancer cells by restoring DUSP4 deficiency. Sci Rep. 2016:6:33035.

29. Span PN, Manders P, Heuvel JJ, Thomas CMG, Bosch RR, Beex LVAM, Sweep CGJ. Expression of the transcription factor Ets-1 is an independent prognostic marker for relapse-free survival in breast cancer. Oncogene. 2002;21:8506-9. 
30. Switzer CH, Cheng RY, Ridnour LA, Glynn SA, Ambs S, Wink DA. Ets-1 is a transcriptional mediator of oncogenic nitric oxide signaling in estrogen receptor-negative breast cancer. Breast Cancer Res. 2012;14:1-13.

31. Zhang Y, Yan LX, Wu QN, Du ZM, Chen J, Liao DZ, Huang MY, Hou JH, Wu QL, Zeng MS. miR-125b is methylated and functions as a tumor suppressor by regulating the ETS1 proto-oncogene in human invasive breast cancer. Cancer Res. 2011;71:3552-62.

32. Merkhofer EC, Cogswell P, Baldwin AS. Her2 activates NF-kB and induces invasion through the canonical pathway involving IKKa. Oncogene. 2010;29:1238
Ready to submit your research? Choose BMC and benefit from:

- fast, convenient online submission

- thorough peer review by experienced researchers in your field

- rapid publication on acceptance

- support for research data, including large and complex data types

- gold Open Access which fosters wider collaboration and increased citations

- maximum visibility for your research: over $100 \mathrm{M}$ website views per year

At BMC, research is always in progress.

Learn more biomedcentral.com/submissions 